\title{
Applications of Psychological First Aid in Disaster and Emergency Situations: Its Relationship with Decision-Making
}

\author{
By Susana Celeste Azzollini* \\ Pablo Domingo Depaula ${ }^{\dagger}$ \\ Alejandro César Cosentino \\ Vera Bail Pupko ${ }^{+}$
}

\begin{abstract}
Many people in the world are highly vulnerable to being affected by events of great vital impact. A disaster, which is known as an unexpected and brutal event, causes great social disorganization and significant psychological disorders. The protocol on Psychological First Aid (PFA) establishes certain actions to take on victims who are in the area of the event. Through these actions, the victims are assisted in a non-invasive protocol and they are helped to feel calm but not passive. The study of the processes of decision-making is a topic of great interest for the advancement of Cognitive Psychology and Neuroscience. Regarding the implementation of PFA in disaster situations, the type of decision-making, analytic or intuitive, could represent an important factor for the effectiveness of the actions of aid provided by volunteers. Thus, the evaluation and decision-making training would be taken as a key factor. In this sense, intuitive or emotional decisions are more effective than analytical ones according to cultural experts who have studied similar situations. This paper presents results and conclusions regarding the associations between the implementation of PFA and the types of decisions made by the volunteers in a simulated disaster. To do so, the use of software, which stages a transport accident, provides the necessary instructions to the users through a set of four videos to be chosen.
\end{abstract}

Keywords: Decision making, Disasters, Psychological First Aid.

\section{Introduction}

Many people in the world are highly vulnerable to being affected by events of great vital impact. In this sense, a disaster is a negative event which is unexpected, brutal and causes significant psychological disorders (Lindell 2011, Lindell et al. 2006). Such situations can be generated from natural or technological threats, such as terrorist attacks, violence between different social groups or the

\footnotetext{
* PhD in Psychology (UBA). National Council of Scientific and Technical Research (CONICET), Psychology Research Institute, Buenos Aires University (UBA), Argentina.

${ }^{\dagger} \mathrm{PhD}$ in Psychology (UBA). National Council of Scientific and Technical Research (CONICET), Psychology Research Institute, Buenos Aires University (UBA), Argentina.

${ }^{*} \mathrm{PhD}$ in Psychology (UP). Center for Social and Humanistic Research for Defense (CISOHDEF), National Defense University (UNDEF), Argentina.

${ }^{+} \mathrm{PhD}$ in Psychology (UK). Center for Social and Humanistic Research for Defense (CISOHDEF), National Defense University (UNDEF), Argentina.
} 
scarcity of vital resources. They also might be related to the field of health, property or welfare (Lindell 2011).

From the psychosocial point of view, the importance of researching disaster is justified by the consequences it has on the physical and mental health of a community. Also important are the agents who manage emergency situations (e.g., firefighters) (Harvey et al. 2015). The importance of these events stems from the fact that they can cause:

- Physical disorders

- Anxiety

- Depression

- Post Traumatic Stress Disorder (PTSD; American Psychiatric Association, 2013).

Figure 1. Emotional Reactions in the PTSD

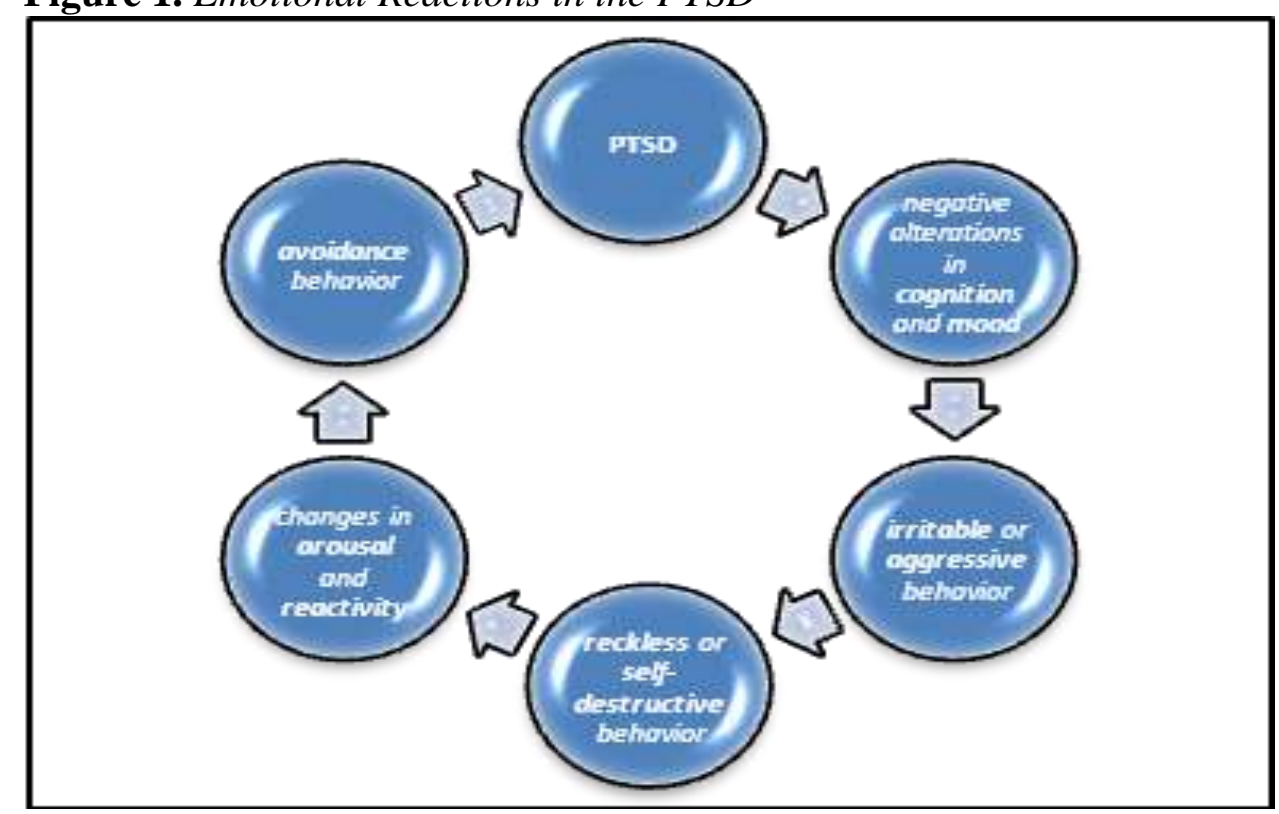

Source: Farchi, 2014.

In contrast, coping with the event in a more adaptive way allows the individual: a) to express fewer disruptive behaviors; b) to control the traumatic situation experience and c) to recover himself (Páez et al. 1995).

In general, by facing adverse events victims assess their resources as insufficient for coping with the demands of the environment. However, their emotional balance, cognitive skills, and therefore their quality and style of life are later affected (Friedman et al. 2011, McNally 2003). For these reasons, psychological intervention in the minutes after an event, through prevention and education, are extremely important. Also it is the setting guidelines and forms of effective action for each situation. 


\section{Neuroscientific Studies and Psychological Approaches of the Previous Phases to PTSD}

Currently, neuroscience makes significant efforts to investigate the neural correlates of PTSD and cognitive functions altered during the phases preceding this mental disorder. Reynaud et al. (2015) conducted a study of brain scan images by using functional Magnetic Resonance Imaging (fMRI) and found changes in the activity of firefighters' brains, which were taken as samples. These professionals had symptoms associated with Acute Stress Disorder (ASD), which takes place during the subsequent month after exposure to a traumatic event. Researchers found high levels of hyperactivity of the amygdala and prefrontal cortex (neurobiological alterations that characterize ASD in particular) as a result of being affected by emotional processing associated with fear. Despite these findings, the authors acknowledge the existence of limitations to testing dysfunctionality during the earliest stages or in the event that will give rise to the disorder mentioned before. Previously, Reynaud et al. (2013) found positive correlations between the levels of the firefighters' resilience and certain neural networks associated with emotional experience, that is the right amygdale and left orbit frontal cortex. They concluded that the demonstration of appropriate emotional responses to stressful situations facilitates coping with aversive events.

In accordance with the described neurobiological abnormalities, the diverse research results show that interventions such as Critical Incident Stress Debriefing (CISD) do not prevent PTSD and it may even be negative for survivors of a disaster (McNally et al. 2003, Rose et al. 2003).

The protocol on Psychological First Aid (PFA) (World Health Organization, War Trauma Foundation and World Vision International 2011) establishes certain actions to take on victims who are in the area of the event. Through these actions, the victims are assisted in a non-invasive way and they are helped to feel calm but not passive (Farchi 2014).

The implementation of the PFA promotes a sense of security and certain level of personal autonomy. It also can reduce the biological aspects of one's own reactions of PTSD (Bryant 2006). Thus by activating areas of the frontal cortex it increases:

- Social support

- Positive coping

- Resilience (Ramirez et al. 2013).

In line with the above premises, Hafstad et al. (2012) conducted a qualitative study. They interviewed 51 parents of Norwegian children, who had been exposed to the Southeast Asia Tsunami in 2004. They noted that the main strategies of parental support applied to their children were related to the recommendations and guidelines for early PTSD intervention and treatment of the National Institute for Clinical Excellence (NICE 2005); that is, to promote the activation of parental interpretation process of emotional reactions and behaviors of discomfort. This prevents the induction of disturbing emotions and provides 
the necessary support for the re-establishment of children's sense of safety. It avoids stimuli that may cause distress in questions concerning to disastrous event that were received from people outside the parental dyad. Also it encourages the resumption of roles and normal daily routines such as the performance at lunch, dinner, homework, rhythm and daily family life function. Finally, it provides alternative coping routines that reduce behaviors or emotions of fear; for example to invite children to swim in the pool in order to overcome the water fear or to establish dialogues with them in the psycho educational mode. The aim is to restructure cognitively the negative thoughts by reviewing the positive aspects of the traumatic event, as it was the case of having the chance to live after surviving a tsunami.

Following this concept, McCabe et al. (2014) describe a model for implementing the PFA, which is focused on training psycho-pedagogical skills and sub-skills based on three domains: a) cognitive domain composed by skills and cognitive processes (i.e., recovered memories of long memory term analysis and deployment of creativity in decision making); b) psychomotor domain equipped with manual or physical skills that emerge when it is applied to the aforementioned technique. It also involves the deployment of social skills of communication and interaction among professionals, volunteers and victims; and finally, c) the affective domain, which is the attitudinal manifestation of emotions, feelings, values and motivations about the work environment.

\section{Decision-making and Psychological First Aid: Conceptual Focus}

The deliberate and thoughtful use of reason, with increased consumption of time, or the deployment of intuitions and emotions that quickly signal a single course of action, constitute the two types of cognitive-affective processes that define decision-making.

While the research conducted over the past three decades has indicated that intuitive decisions lead to faster responses, it is not yet known exactly whether emotional intuition or deliberate analysis produce greater decisional effectiveness (Laborde and Raab 2013, Raab and Laborde 2011). According to these authors, elections or decisions of the intuitive type represent unconscious associations between perceived situations and particular courses of action characterized by the subjective experience of feelings of visceral type or gut feelings (Gigerenzer 2008, Loewenstein 1996). They include somatic states (Bechara 2004, Damasio 2010, 2014, Lieberman 2007), humor, attitudes, evaluations and preferences (Betsch 2004, Betsch and Kunz 2008). Other authors, however, argue that firefighters and nurses who take decisions against domestic accidents, health emergencies and/or natural disasters, reach higher levels of decisional effectiveness when they deploy rapid intuitive associations formed by previous experiences that are grouped unconsciously in the form of pattern recognition, in other words, a recognition-primed decision model (RPD) (Klein 2003, 2008).

Comfort (2007) discusses the importance of cognition in the management 
of crises and emergencies. He considers that although decision-making represents a topic or cognitive process of great importance in this area, this construct has been sufficiently studied under conditions of uncertainty, but it has not been in relation to the events of crisis and disaster. For this reason, the author appreciates the incorporation of training programs for emergency personnel based on some aspects of RPD, Klein's (2008) model of bounded rationality, and intuition coined by Simon (1957). The idea is founded in the fact that environmental conditions in highly stressful urgent situations faced by decision makers should be carried out on the application of actions from previous experience or scheduled training (Depaula and Azzollini 2016, Lipshitz et al. 2001, Salas et al. 2010). Other authors (Gardner et al. 2012) indicate that the use of emotions or reason for decisionmaking in highly stressful scenarios has different implications for individual adaptation.

In addition, the intuitive type processing may depend on the nature of the context and the specific profession decider. Also, the effectiveness could be improved with previous training (Sinclair 2010).

However, the complexity and risk to life that characterizes a context in which a disastrous event takes place leads to seeking valid answers to the question about the types of decisions which are more effective when the first intervention is provided to victims in an event of great impact. Hereafter, a study is presented to refer to such a scientific problem.

This research presents preliminary results and conclusions regarding the associations between the implementation of the PFA and the types of decisions made by the volunteers during a simulated disaster situation. To do so, software that stages a transport accident was used to provide the necessary instructions through a set of four videos to be chosen.

\section{Method}

A quantitative, transectional type study with experimental design was carried out. The population and sample was integrated by Argentine firefighters volunteers $(\mathrm{N}=40)$ with experience in disaster situations $(\mathrm{n}=24)$, and no experience in disaster situations $(n=16)$. The techniques and instruments used were Interactive Software Psychological First Aid (Interactive First Aid Psychological Software, SIPAPSI, in Spanish, Torres et al., 2015) and Sociodemographic Survey (battery of psychological tests). The SIPAPSI was used to apply the experimental treatments below.

The data collected through the mentioned techniques would be analyzed later by a statistical analysis program called SPSS 22.0., used especially for specific studies of social sciences.

In the first phase of the study, participants received an initial slogan, which began the experiment, by receiving a piece of news from the media about the catastrophe of a serious rail accident. SIPAPSI screen shows, to the experimental subjects, the catastrophe in which they have to assist the victims of the event. 
So, they had to respond to the experimental task in order to assist a victim of the disaster (see Figure 2).

\section{Figure 2. Instruction of the Experimental Task}

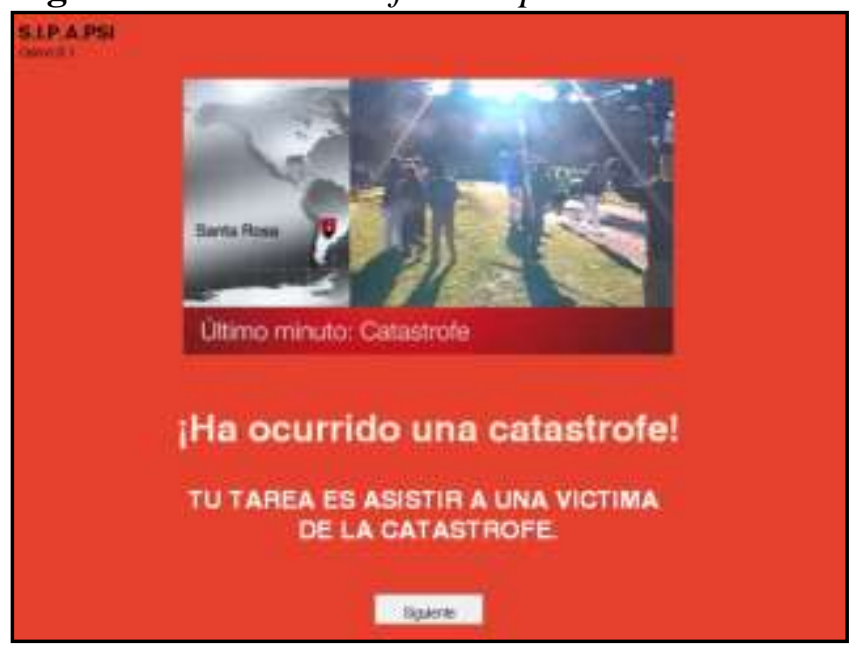

Then, experimental subjects received instructions and a video test to become familiar with the use of the software. They were informed that they would be presented several sets of four videos in which they had to choose the right video and the PFA technical action that is closest to their intervention in a disaster situation. The dependent variable, i.e., the effectiveness of PAP actions, was the amount of successes achieved in all of the sets of video. The content of the scenes arising from each video and the most effective PFA action provided in each set were determined through a trial of two experts in the technical protocol corresponding help.

On the other hand, the operationalization of the independent variable represented by the type of decisions taken during the proposal experimental task (intuitive or emotional vs. analytical or rational) was given by the manipulation of the decision making process. Participants received, prior to the display of each set of videos, instructions for one of the experimental groups corresponded to an emotional decisional induction: they had to decide according to what they "feel emotionally". The other experimental group corresponded to a rational decisional induction: they decide according to what they "think rationally" (Betsch and Kunz model 2008). So, preliminary screen presentation of each video set. The instructions can be visualized according to induction type (see Figure 3). 
Figure 3. Decisional Induction

Usted debe basar su decisión en lo que

sienta emocionalmente

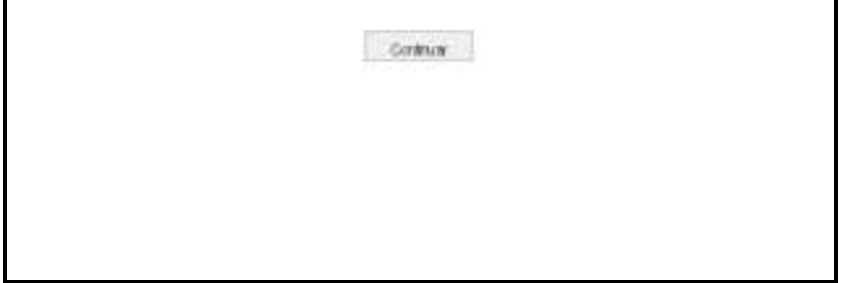

With these first indications, the first set of four videos was presented on the screen; video screen shows four possible PFA actions. Each of them has their own reproduction buttons with the question "What do I do?" and each participant had to play each video to watch the scenes and they could play it again at random according to their subjective needs. Finally they had to select the chosen action by clicking on the button under the desired video (Figure 4).

\section{Figure 4. Psychological First Aid Actions}

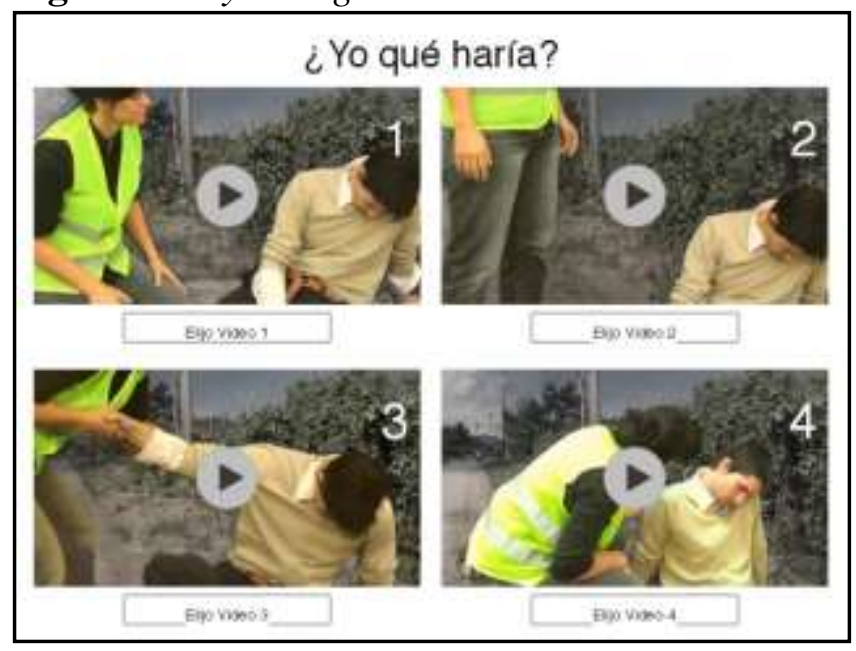

If the selected video was correct, by following the course of action of the PFA protocol, the system recorded the right option and it did the same if the option was incorrect. Later, they were presented the emotional or rational decision-making induction again before the screen showed a new set of four videos. Participants then would choose actions that were described in the other sets of videos to complete the experimental task. Likewise, the system recorded the decision making time of each performance and timed them since the appearance of the first video until participants clicked the chosen option.

In a second and final phase of the study participants responded to a survey 
of socio-demographic data and a battery of psychometric tests that compiled information about other psychological variables of interest (e.g., personality, urgent decision making styles, coping strategies, openness to other culturally diverse, etc.).

To measure the types of decision-making that address urgent situations, the Basis for Urgent Decisions under Extreme Circumstances Inventory (BUDECI) (Cosentino et al. Azzollini, Depaula and Castillo 2017) was administered. This instrument is a short protocol made up of eight items designed to evaluate, through two dimensions, the personal tendency to take rational urgent decisions (DUR for its acronym in Spanish) and rational affective decisions (DUA for its acronym in Spanish) under extreme situations. The BUDECI was validated using samples of university military students, peacekeeping soldiers and general population. The results of BUDECI validation in the Argentine population showed evidence of acceptable levels of reliability and the structural validity in the known group: military vs. civilian. The reliability coefficients for these sample dimensions were .84 for DUA and .76 for DUR.

The survey and psychometric battery was presented in a digital format through the computer system support SIPAPSI. The administration time to complete the questionnaires was 30 to 60 minutes approximately.

The registration of all the experimental and psychometric data was stored in a database of Microsoft Office Excel exportable to the statistical analysis program SPSS 22.0.

Participants were evaluated through consistent technological resources with the required hardware according to the characteristics of the sample and the optimal management of SIPAPSI - computers and headphones - by which experimental treatments were presented with the help of the software. Experimental subjects were told beforehand that the test was anonymous and they could stop their participation at any time during the experiment. In addition, they signed the corresponding consent.

\section{Results}

A t test of mean differences was performed to analyze differences in the number of the correct responses between emotional decisional induction (decision based on "feels emotionally") and rational decisional induction (decision based on "think rationally") (Betsch and Kunz 2008). The results showed that the average of rational induction was higher than the average of correct responses in emotional induction and these differences were statistically relevant (emotional $M=5.33$; rational $M=6.75 ; t=-1.47 ; p<.05)$.

Another goal was to corroborate the existence of statistically significant associations between the dimensions of BUDECI test (Cosentino et al. 2017) Rational Urgent Decisions with the number of correct answers. The results showed the existence of a positive and statistically significant association between the two variables $(r=.59 ; p<.001)$.

Finally, there were statistically significant differences between trained and 
not trained firefighters $(F=12.36 ; p<.01)$.

\section{Discussion}

This research develops some concepts to reflect on the inclusion of PFA in disaster and catastrophe management with the aim of scientifically consolidating an important tool for the early assistance of victims and prevention of PTSD. In this regard, the PFA is a technical device that is trainable in volunteers who are going to act in situations of high vital impact.

Having this general overview, the processes and styles of decisions made by the volunteers during their training and during the event constitute an important aspect to be considered in order to ensure the highest levels of effectiveness in implementing PFA.

The results of the study indicate that there are differences in the effectiveness of the implementation of the PFA and a better performance is associated with analytic or deliberate decision-making. They respond to an experimental induction of rational type associated with the predominance of a personal style or personal tendency to make decisions in a rational rate against extreme situations that require an urgent temporal action. Both decision-making patterns were present in the PFA volunteer participants who were more effective by choosing the option of psychological assistance to victims simulated through SIPAPSI. There are also differences in the performance of trained subjects who applied this technique. They do it in a more effective way.

The results fit with the findings of a previous experiment by Cosentino et al. (2016) in which the decision was focused on peacekeeping soldiers who provide humanitarian assistance in conflicts under UN mandate. They are compared to inexperienced military students who have no peacekeeping training. Software was used, including videos that staged different situations with high or low level of cultural saturation (Depaula et al. 2012). The authors analyzed the decisions that showed situations loaded with and without elements of the Haitian culture where the subjects had to participate later in the UN mission. A $2 \times 2 \times 2$ factorial design (independent variables: decisional mode, training as peacekeeping soldier and cultural saturation of the observed situation - i.e., level of development of cultural aspects of the Haitian region -; dependent variable: response intervention in the observed situation) showed fewer interventions by experts subject when they made decisions through an experimental instruction (rational one). This instruction was identical to the one used in this study (i.e., rational decisional induction: "think rationally"). Additionally, a higher level of DUA (i.e., affective urgent decisions measured by the use of BUDECI) showed a greater number of interventions in untrained subjects. By having these results, the study concluded that expert subject who were trained in international peacekeeping missions were more rational or analytical and they had less interventions in situations of high uncertainty and cultural saturation. The result is expected, as it is a form to show respect for the host culture. Depaula and Azzollini (2016) observed that blue helmets with a 
greater number of previous peacekeeping missions deployed in Haiti took cultural decisions that show a higher level of effectiveness.

Different to some authors who assume that in some specific domains in the form of primary expertise, such as chess, applied diagnosis to intensive care, mathematics, etc., the discrimination on analytical thinking is fast and intuitive (Campitelli et al. 2015, Thompson et al. 2014). A meta-analysis based on 88 published and unpublished studies by Macnamara et al. (2014) until March 2014, plus 111 independent samples with a grand total of 11.135 participants, showed positive correlations between deliberate practices and effective performance achieved in domains such as music, games, sports, education and professions. The results indicated that the use of deliberation or analytical thinking explained $12 \%$ of the total variance in performance.

Taking into account the above studies, one might think that in complex cultural situations and in disaster situations in which PFA actions are applied, it would be, on one hand, more effective to implement decision-making when there is a higher level of training and expertise. On the other hand, with analytical and deliberate processing, PFA volunteers could express better reflective understandings of the victim by facilitating a "refractory mode" that activates areas of the frontal cortex (Farchi 2014, Ramirez et al. 2013) and by providing a deliberate activation and conscious interpretation of the emotional reactions processes and behaviors of discomfort (Hafstad et al. 2012); based on the acquisition of scheduled competencies or cognitive domains (McCabe et al. 2014). Such conditions allow the victims return to the feeling of security under a framework of psycho educational preventive approach to PTSD.

Finally, this study's main limitation is the shortage of participants who made up the sample. Thus, future studies should maximize the evaluated number of subjects to confirm the current results.

\section{References}

American Psychiatric Association (2013) Diagnostic and Statistical Manual of Mental Disorders, 5th ed. Washington: DC: American Psychiatric Publishing.

Bechara A (2004) The role of emotion in decision-making: Evidence from neurological patients with orbitofrontal damage. Brain and Cognition 55(1): 30-40.

Betsch C (2004) Präferenz für intuition und deliberation. Inventar zur erfassung von affekt- und kognitionsbasiertem entscheiden [Preference for intuition and deliberation (PID): An inventory for assessing affect- and cognition-based decision-making]. Zeitschrift für Differentielle und Diagnostische Psychologie 25: 179-197.

Betsch C, Kunz JJ (2008) Individual strategy preferences and decisional fit. Journal of Behavioral Decision Making 21(5): 532-555. -

Betsch C, Kunz, JJ (2008) Individual strategy preferences and decisional fit. Journal of Behavioral Decision Making 21(5): 532-555.

Bryant RA (2006) Cognitive behavior therapy: Implications from advances in neuroscience. In N Kato, M Kawata, RK Pitman (eds) PTSD: Brain mechanisms and clinical implications, 255-270. Tokyo: Springer-Verlag. 
Campitelli G, Connors MH, Bilalić M, Hambrick DZ (2015) Psychological perspectives on expertise. Frontiers in Psychology 6: 1-4.

Comfort LK (2007) Crisis Management in Hindsight: Cognition, Communication, Coordination, and Control. Public Administration Review, Special Issue 189-197.

Cosentino AC, Azzollini SC, Depaula PD, Castillo SE (2017) Assessment of the affective and rational bases for urgent decision-making under extreme circumstances. Análise Psicológica 35(4): 543-556.

Cosentino AC, Azzollini SC, Depaula PD, Castillo SE (2016) Toma de decisión según racionalidad/afectividad, entrenamiento y saturación cultural en situaciones multiculturales: Un estudio experimental con soldados para la paz [Decision making under rationality/affectivity, training, and cultural saturation in multicultural situations: an experimental study with peacekeepers]. Interdisciplinaria 33(2): 283298.

Damasio A (2010) El error de Descartes: la emoción, la razón y el cerebro humano [Descarte's error: emotion, reason and the human brain]. Buenos Aires: Paidós.

Damasio A (2014) En busca de Spinoza: Neurobiología de la emoción y los sentimientos [Looking for Spinoza: Joy, sorrow, and the feeling brain]. Buenos Aires: Paidós.

Depaula PD, Azzollini SC (2016) Efectividad decisoria en ambientes culturales diversos y experiencias previas en misiones de paz: Un estudio correlacional con cascos azules argentinos [Effective decision making in diverse cultural environments and previous experiences in peacekeeping missions: A correlation study with argentine peacekeepers]. Psicodebate 6(1): 83-108.

Depaula P, Torres JA, Piñeyro DR, Cosentino AC, Clotet CI, Castillo S (2012, November) Desarrollo de un software para la evaluación de la toma de decisiones en contextos de incertidumbre cultural [Development of software for the evaluation of decision making in contexts of cultural uncertainty]. Poster presented at the IV International Congress of Research and Professional Practice in Psychology, XIX Research Conference, VIII Meeting of Researchers in Psychology of MERCOSUR, organized by the Research Secretariat of the Faculty of Psychology of the Buenos Aires University, Ciudad Autónoma de Buenos Aires, Buenos Aires.

Farchi M (August, 2014) Introducción a la primera ayuda psicológica en situaciones de desastres y emergencias masivas [Introduction to the first psychological help in situations of disasters and massive emergencies]. In S Azzollini (Presidency), Crisis management and trauma prevention in catastrophes and emergencies. Seminar held in Buenos Aires, Argentina.

Friedman MJ, Resick P, Bryant R, Strain J, Horowitz M, Spiegel D (2011) Classification of trauma and stressor-related disorders in DSM-5. Depression and Anxiety 28(9): 737-49.

Gardner KJ, Archer J, Jackson S (2012) Does maladaptive coping mediate the relationship between borderline personality traits and reactive and proactive depression? Aggressive Behavior 38: 403-413. doi:10.1002/ab.21437

Gigerenzer G (2008) Decisiones instintivas. La inteligencia del inconsciente [Gut feelings. The intelligence of the unconscious]. Barcelona: Ariel.

Hafstad GS, Haavind H, Jensen TK (2012) Parenting After a Natural Disaster: A Qualitative Study of Norwegian Families Surviving the 2004 Tsunami in Southeast Asia. Journal of Child and Family Studies 21: 293-302.

Harvey SB, Milligan-Saville JS, Paterson HM, Harkness EL, Marsh AM, Dobson M et al. (2015) The mental health of fire-fighters: An examination of the impact of repeated trauma exposure. Australian and New Zealand Journal of Psychiatry 23: 1-10.

Klein G (2003) Intuition at work: Why developing your gut instincts will make you better at what you do. New York, NJ: Currency Doubleday. 
Klein G (2008) Naturalistic Decision Making. Human Factors 50(3): 456-460.

Laborde S, Raab M (2013) The Tale of Hearts and Reason: The Influence of mood on Decision Making. Journal of Sport and Exercise Psychology 35: 339-357.

Lieberman MD (2007) Social Cognitive Neuroscience: A Review of Core Process. Annual Review of Psychology 58: 259-289.

Lindell MK (2011) Disaster studies. Sociopedia.isa 1-18.

Lindell MK, Prater CS, Perry RW (2006) Fundamentals of Emergency Management. Emmitsburg, MD: Federal Emergency Management Agency Emergency Management Institute. Retrieved from http://bit.ly/2iSPiLD.

Lipshitz R, Klein G, Orasanu J, Salas E (2001) Focus Article: Taking Stock of Naturalistic Decision Making. Journal of Behavioral Decision Making 14: 331-352.

Loewenstein G (1996) Out of Control: Visceral Influences on Behavior. Organizational Behavior and Human Decision Processes 65(3): 272-292.

Macnamara BN, Hambrick DZ, Oswald FL (2014) Deliberate Practice and Performance in Music, Games, Sports, Education, and Professions: A Meta-Analysis. Psychological Science 1: 1-11.

McCabe OL, Everly Jr GS, Brown LM, Wendelboe AM, Abd Hamid NH, Tallchief VL et al. (2014) Psychological First Aid: A Consensus-Derived, Empirically Supported, Competency-Based Training Model. American Journal of Public Health 104(4): 621628.

McNally R (2003) Psychological mechanisms in acute response to trauma. Biological Psychiatry 53: 779-788.

McNally RJ, Bryant RA, Ehlers A (2003) Does early psychological intervention promote recovery from posttraumatic stress? American Psychological Society 4(2): 45-79.

National Institute for Clinical Excellence (NICE) (2005) Post-traumatic stress disorder: The management of PTSD in adults and children in primary and secondary care. London: Gaskell and the British Psychological Society.

Páez D, Arroyo E, Fernández I (1995) Catástrofes, situaciones de riesgo y factores psicosociales [Catastrophes, risk situations and psychosocial factors]. Mapfre Seguridad 57: 43-55.

Raab M, Laborde S (2011) When to Blink and When to Think: Preference for Intuitive Decisions Results in Faster and Better Tactical Choices. Research Quarterly for Exercise and Sport 82(1): 89-98.

Ramirez M, Harland K, Frederick M, Shepherd R, Wong M, Cavanaugh JE (2013) Listen protect connect for traumatized schoolchildren: a pilot study of psychological first aid. BMC Psychology 26(1): 1-9.

Reynaud E, Guedj E, Souville M, Trousselard M, Zendjidjian X, El Khoury-Malhame M et al. (2013) Relationship between emotional experience and resilience: An fMRI study in fire-fighters. Neuropsychologia 51: 845-849.

Reynaud E, Guedj E, Trousselard M, El Khoury-Malhame M, Zendjidjian X, Fakra E et al. (2015) Acute stress disorder modifies cerebral activity of amygdala and prefrontal cortex. Cognitive Neuroscience 6(1): 39-43.

Rose S, Bisson J, Wessely S (2003) A systematic review of single-session psychological interventions ("debriefing") following trauma. Psychotherapy and Psychosomatics 72: 176-184.

Salas E, Rosen MA, DiazGranados D (2010) Expertise-Based Intuition and Decision Making in Organizations. Journal of Management 4(36): 941-973.

Simon HA (1957) Models of Man: Social and Rational. New York: Wiley.

Sinclair M (2010) Misconceptions about Intuition. Psychological Inquiry: An International Journal for the Advancement of Psychological Theory 21: 378-386.

Thompson MB, Tangen JM, Searston RA (2014) Understanding expertise and non- 
analytic cognition in fingerprint discriminations made by humans. Frontiers in Psychology 5: 1-3.

Torres JA, Azzollini S, Depaula P, Bail Pupko V, Cosentino A, Becerra L et al. (2015, November) Toma de decisiones en voluntarios que realizan la primera ayuda psicológica en situaciones de catástrofe y emergencia [Decision making in volunteers who perform the first psychological help in situations of catastrophe and emergency]. Poster presented in the VII International Congress of Research and Professional Practice in Psychology, XXII Research Conference, XI Meeting of Research in Psychology of MERCOSUR, organized by the Research Secretariat of the Faculty of Psychology of the Buenos Aires University, Ciudad Autónoma de Buenos Aires, Buenos Aires.

World Health Organization, War Trauma Foundation and World Vision International (2011) Psychological first aid: Guide for field workers. Geneva: WHO. 
